\title{
Segregation of eosinophil proteins in alveolar macrophage compartments in chronic eosinophilic pneumonia
}

\author{
A Janin, G Torpier, P Courtin, M Capron, L Prin, A-B Tonnel, P-Y Hatron, B Gosselin
}

\begin{abstract}
Background The objective was to characterise the process and consequences of eosinophil activation and lysis in patients with chronic eosinophilic pneumonia and to compare them with those in patients with eosinophil pulmonary infiltrates from other causes.

Methods Cells from bronchoalveolar lavage fluid of four patients with chronic eosinophilic pneumonia and four patients with eosinophilic infiltrates associated with Sjögren's syndrome, drug hypersensitivity pneumonia, postradiotherapy fibrosis, and pulmonary disease associated with graft versus host disease were studied ultrastructurally and with immunogold labelled antibodies directed against eosinophil proteins: major basic protein, eosinophil cationic protein, and Charcot-Leyden crystal protein. The concentration of eosinophil cationic protein was also measured in bronchoalveolar fluid.
\end{abstract}

Results In the four patients with chronic eosinophilic pneumonia, ultrastructural studies demonstrated numerous lysed eosinophils. Further, three released eosinophil proteins were detected in distinct cytoplasmic structures in alveolar macrophages. These features were not found in the four patients with eosinophilic pulmonary infiltrates from other causes.

Conclusion Eosinophils in chronic eosinophilic pneumonia show signs of activation with release of eosinophil proteins. The appearance of three of these eosinophil proteins in different macrophage compartments suggests that macrophage uptake, with or without intracellular transport of released eosinophil proteins, involves separate mechanisms. This interaction does not lead to macrophage lysis, however, and one or more of these eosinophil proteins might directly affect macrophage function.

(Thorax 1993;48:57-62)

Chronic eosinophilic pneumonia is characterised by a high eosinophil count in bronchoalveolar lavage fluid, ${ }^{12}$ severe constitutional symptoms and pulmonary infiltrates in the upper lobes. ${ }^{34}$ Steroid therapy can lead to a dramatic response, but prolonged therapy is frequently required to avoid recurrence..$^{5-7}$

Morphological, biochemical, and functional studies of eosinophils from blood and tissues of patients with diseases related to eosinophils have shown that they differ from normal eosinophils in several ways. $^{8}$ A predominant "hypodense" alveolar eosinophil population has been found in lavage fluid of patients with active chronic eosinophilic pneumonia. ${ }^{1}$ This density difference ("hypodense" versus "normodense" eosinophils) identifies eosinophil subpopulations with differing immunological and metabolic characteristics. ${ }^{9}$ Past studies have suggested that tissue eosinophils in patients with chronic eosinophilic pneumonia are activated, but the interpretation of these studies was limited as they were performed on purified blood or lavage fluid eosinophil populations and, therefore, did not reveal the fate of released eosinophil granule components.

Analyses of ultrastructural features in chronic eosinophilic pneumonia have shown alterations in eosinophil fine structure, ${ }^{1011}$ and the presence of eosinophil granules as well as Charcot-Leyden crystals in pulmonary macrophages, ${ }^{12}{ }^{13}$ suggesting an interaction between the two types of cells. Eosinophil granule proteins and Charcot-Leyden crystal protein are now well characterised, ${ }^{14}$ and have recently been sequenced. Eosinophil cationic proteins (eosinophil peroxidase, eosinophil cationic protein (ECP), major basic protein (MBP) are considered the main effectors of eosinophil function in hypersensitivity and cytotoxicity reactions. ${ }^{14-17}$ In vitro assays have shown that the release of these eosinophil granule proteins can be selective, and is triggered by stimulation of one or several of the membrane receptors. ${ }^{1819}$

The purpose of this study was to localise eosinophil proteins in cells of bronchoalveolar lavage fluid at the ultrastuctural level and to assess eosinophil changes and possible interactions with other cells in fluid obtained by bronchoalveolar lavage in patients with chronic eosinophilic pneumonia. Therefore we combined electron microscopy and immunogold detection of eosinophilic cationic protein, major basic protein, and Charcot-Leyden crystal (CLC) proteins to study the cells obtained by bronchoalveolar lavage from four patients with chronic eosinophilic pneumonia and from four others with eosinophilic pulmonary infiltrates due to other causes. All were nonsmokers. 
Clinical, radiological, and biological data in the eight patients

\begin{tabular}{|c|c|c|c|c|c|c|c|c|}
\hline \multirow[b]{2}{*}{ Patient No: } & \multicolumn{4}{|c|}{ Chronic eosinophilic pneumonia } & \multicolumn{4}{|c|}{$\begin{array}{l}\text { Eosinophil pulmonary infiltrates from } \\
\text { other causes }\end{array}$} \\
\hline & 1 & 2 & 3 & 4 & 5 & 6 & 7 & 8 \\
\hline Age (years) & 32 & 41 & 37 & 44 & 53 & 42 & 54 & 21 \\
\hline Sex & $\mathbf{F}$ & $M$ & $\mathbf{M}$ & $M$ & $\mathbf{F}$ & $\mathbf{F}$ & $\mathrm{F}$ & $\mathbf{M}$ \\
\hline $\mathrm{PaO}_{2}(\mathrm{kPa})$ & $8 \cdot 26$ & $10 \cdot 13$ & 8.93 & $8 \cdot 66$ & $10 \cdot 93$ & $9 \cdot 46$ & $9 \cdot 20$ & $7 \cdot 86$ \\
\hline Radiographic infiltrate & Apical & Diffuse & Apical & Diffuse & Diffuse & Diffuse & Diffuse & Basal \\
\hline Blood eosinophils (\%) & 32 & 35 & 42 & 48 & 10 & 34 & 3 & 12 \\
\hline Blood eosinophils $\left(\times 10^{6} / 1\right)$ & 3.99 & $6 \cdot 80$ & $8 \cdot 40$ & $9 \cdot 50$ & $9 \cdot 50$ & $4 \cdot 75$ & $2 \cdot 50$ & $1 \cdot 03$ \\
\hline BAL total cells $\left(\times 10^{5}\right)$ & 160 & 120 & 172 & 98 & 75 & 100 & 82 & 90 \\
\hline BAL eosinophils (\%) & 32 & 40 & 51 & 43 & 19 & 39 & 12 & 28 \\
\hline BAL macrophages (\%) & 61 & 55 & 42 & 51 & 44 & 53 & 62 & 58 \\
\hline BAL lymphocytes (\%) & 6 & 5 & 7 & 5 & 35 & 4 & 12 & 12 \\
\hline BAL neutrophils (\%) & 1 & 0 & 0 & 1 & 2 & 4 & 14 & 2 \\
\hline BAL ECP level $(\mu \mathrm{g} / \mathrm{ml})$ & 31 & ND & 29 & 33 & 5 & 10 & 8 & 9 \\
\hline
\end{tabular}

BAL - bronchoalveolar lavage fluid; ECP—eosinophil cationic protein; ND—not determined

\section{Patients and methods}

\section{PATIENTS}

Four patients (cases 1-4, table) presented with most of the usual symptoms of chronic eosinophilic pneumonia, i.e. weight loss, fever, night sweats, dry cough, and severe dyspnoea without wheeze, but with widespread inspiratory crackles. $\mathrm{PaO}_{2}$ ranged from $8 \cdot 26$ to $10 \cdot 13 \mathrm{kPa}$ on air at rest. This chronic, progressive illness did not improve after symptomatic treatment or antibiotics. Chest radiographs revealed dense infiltrates in the upper lobes in cases 1 and 3, and diffuse pulmonary infiltrates in cases 2 and 4. Blood eosinophil counts were high, ranging from 3.99 to $9.5 \times 10^{6} / 1$ eosinophils. ${ }^{3}$ All patients were free of allergic, drug-induced or systemic diseases, and tests for fungal and parasitic infections were negative. All patients underwent bronchoalveolar lavage before steroid treatment was initiated. A transbronchial biopsy was performed in case 2 , but because of hypoxia and the potential risk of pneumothorax bronchoalveolar lavage was preferred to transbronchial or open lung biopsy at this initial stage in the three other cases.

A control group comprised four nonsmoking patients (cases 5-8, table) with eosinophilic pulmonary infiltrates from other origins. These patients had, respectively, Sjögren's syndrome, drug hypersensitivity pneumonitis, postradiotherapy fibrosis and pulmonary involvement associated with graft-versus-host disease. None of these patients were receiving steroids when bronchoalveolar lavage was performed. Three healthy non-smoking subjects, two men and one woman, aged 25,28 , and 32 years, underwent bronchoalveolar lavage with their informed consent to measure levels of ECP in their lavage fluids.

\section{BRONCHOALVEOLAR LAVAGE}

Bronchoalveolar lavage was performed before steroid therapy began. After local anaesthesia, the fibreoptic bronchoscope was inserted through the nose and wedged in a distal portion of a segmental bronchus, at the site of maximum infiltrate in each case. Five aliquots each of $50 \mathrm{ml}$ of sterile $0.9 \%$ saline were instilled through the bronchoscope. The volume of lavage fluid recovered varied between 190 and $210 \mathrm{ml}$. The alveolar fluid cells recovered by gentle aspiration were washed and resuspended in Hank's balanced salt solution with $1 \%$ bovine serum albumin. Total cell counts were determined using a haemocytometer. A cytocentrifuge slide was made and stained using the May-Grünwald-Giesma stain for differential cell counting. The remaining cells were centrifuged at $500 \mathrm{~g}$ for 10 minutes, and the pellet was fixed in cacodylate buffer containing $1 \%$ glutaraldehyde at $4^{\circ} \mathrm{C}$.

\section{MEASUREMENT OF ECP IN BRONCHOALVEOLAR LAVAGE FLUID}

For three patients with chronic eosinophilic pneumonia (cases 1, 3, and 4), the four patients with eosinophilic pulmonary infiltrates from other causes, and three healthy control subjects, levels of ECP in bronchoalveolar lavage fluid were measured in duplicate with a radioimmunoassay, using the method recommended by the manufacturer (ECP RIA Pharmacia, Uppsala, Sweden).

ELECTRON MISCROSCOPY

The pellet was cut into small specimens after aldehyde fixation. This was followed by osmium tetroxide fixation. Half of the specimens were embedded in araldite and processed further for conventional electron microscopy. The other specimens were embedded in Lowicryl K4M for immunocolloidal gold labelling.

\section{IMMUNOGOLD LABELLING}

Ultrathin sections on nickel grids were incubated for 10 minutes on a drop of Tris- $\mathrm{HCl}$ buffered saline $(20 \mathrm{mmol} / 1$ Tris $\mathrm{HCl}, 0.5 \mathrm{~mol} / 1$ $\mathrm{NaCl}$ ) $\mathrm{pH} 7 \cdot 4$ (TBS) containing $5 \%$ (w:v) ovalbumin, supplemented with $1 \%$ heat inactivated normal goat serum. This was followed by incubation with polyclonal rabbit antibodies to human MBP and CLC protein (kindly provided by Dr G J Gleich, Rochester, Minnesota), or mouse monoclonal antibody to ECP (EG2, kindly provided by Dr Po Chun Tai, London, UK) used as primary reagents. The grids were then rinsed with TBS-ovalbumin and incubated on a drop of the $10 \mathrm{~nm}$ gold conjugated goat anti-rabbit or mouse IgG $(1: 40)$ (Janssen Pharmaceutica, Beerse, Belgium). After 1 hour incubation at room 


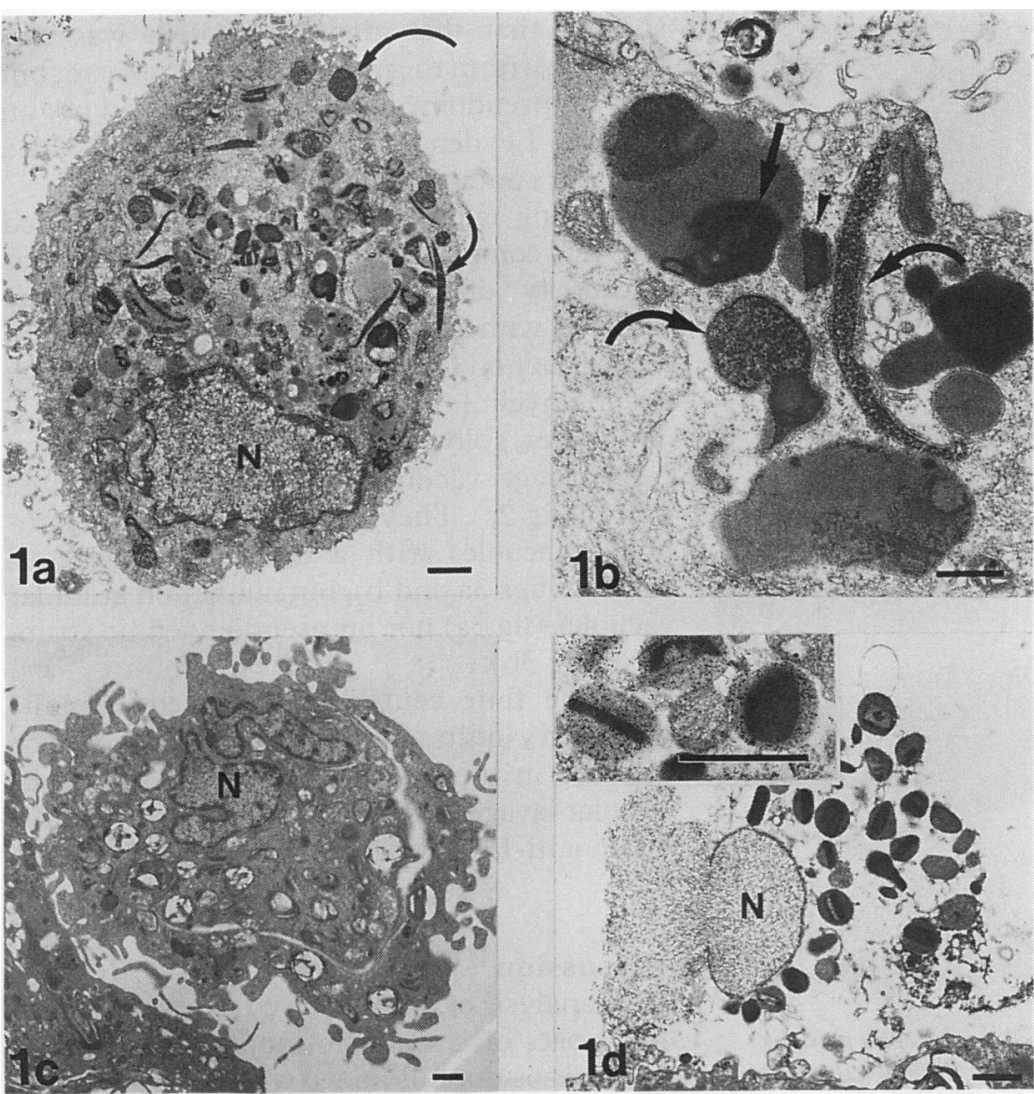

Figure 1 Ultrastructural features of lavage cells. (a) Low magnification of a macrophage showing numerous phagolysosome vacuoles with various shapes. Unusual long or round granular vacuoles (curved arrows) are present, bar $=1 \mu \mathrm{m}$. (b) Higher magnification of a cytoplasmic area showing membranous pseudomyelinic structures (straight arrow) and granular long or round shaped vacuoles (curved arrows) in close vicinity to remnants of an eosinophil granule (arrowhead), bar $=1 \mu \mathrm{m}$. (c) Control: normal alveolar macrophage from a non-smoker patient, bar $=1 \mu \mathrm{m}$. (d) Eosinophil lysis: necrotic nucleus and free extracellular eosinophil granules frequently observed in bronchoalveolar lavage fluid of chronic eosinophilic pneumonia. Insert: immunostaining with anti-eosinophil cationic protein antibody: gold particles are detected on the matrix of the free eosinophil granules, bar $=1 \mu \mathrm{m}$.

temperature, sections were thoroughly washed with TBS, postfixed for 10 minutes in TBS containing $2 \%$ glutaldehyde, and washed again with distilled water. Finally, the sections were subjected to silver enhancement according to a modification of Danscher's silver lactate hydroquinone physical developer.

The specificity of the immunostaining was tested by omitting the first antibody and substituting the specific antibodies with the preimmune serum or with unrelated antibodies whose labelling had been analysed previously. ${ }^{20}$ Lowicryl sections were stained with uranyl acetate and lead citrate before examination with a Philips EM 420 electron microscope.

\section{Results}

In all four cases of chronic eosinophilic pneumonia, bronchoalveolar lavage fluid showed similar features for macrophage fine structure, extracellular eosinophil components and distribution of MBP, ECP and CLC into macrophage cytoplasmic compartments.

FINE STRUCTURE OF MACROPHAGES IN BRONCHOALVEOLAR LAVAGE FLUID

Ultrastructural examination of the bron- choalveolar lavage fluid in the four cases of chronic eosinophilic pneumonia showed numerous cytoplasmic vacuoles containing a granular substance (fig la) in approximately $80 \%$ of macrophages. These vacuoles were round or elongated (fig $1 \mathrm{~b}$ ). Some of them were close to altered phagocytosed eosinophil granules (fig 1b) or Charcot-Leyden crystals.

Macrophages from the four control cases of eosinophilic pulmonary infiltrate did not contain any vacuoles with coarse granular material or Charcot-Leyden crystal, as illustrated in fig 1c.

Other cytoplasmic components (pseudomyelinic structures, electron dense bodies of various shapes) were common to macrophages from bronchoalveolar lavage fluid in all the cases studied.

\section{FINE STRUCTURE OF EOSINOPHILS IN}

BRONCHOALVEOLAR LAVAGE FLUID

In the lavage specimens from the four cases of chronic eosinophilic pneumonia, eosinophils were numerous and showed alterations of the nucleus and cytoplasm. A precise quantitative assessment was not possible by electron microscopy, but differential counts showed a high percentage of eosinophils (32-51\%; median, $42.5 \%$ ), significantly higher than in the control group (19-39\%; median, $24.5 \%$ ). More than half of the eosinophils observed in the patients with chronic eosinophilic pneumonia were lysed with a necrotic nucleus (fig 1d), cytoplasmic degeneration, and free eosinophil granules. Condensation of the chromatin typical of apoptotic bodies was not observed.

Immunostaining showed that MBP was located in central cores of free eosinophil granules, with a lower concentration of gold particles when the central cores were altered. ECP was found on the matrix of free eosinophil granules, but also in the extracellular space (fig $1 \mathrm{~d}$, insert). With anti-CLC antibodies very few gold particles were detected in the extracellular areas.

Comparative studies performed in the four control cases of eosinophilic pulmonary infiltrates showed that free eosinophil granules were only observed in case 6 ; they were few and extracellular gold particles were only observed with anti-CLC antibodies. In the three other cases, a few intracytoplasmic granules had a central core of irregular density, but no extracellular gold particles were observed with any of the three antibodies.

\section{MEASUREMENT OF ECP IN BRONCHOALVEOLAR} LAVAGE FLUID

The release of ECP in to extracellular space could not be quantified with immunogold labelling, but measurement of ECP levels in bronchoalveolar lavage fluid showed high values in chronic eosinophilic pneumonia (31 $\mu \mathrm{g} / \mathrm{ml}$; range $29-33 \mathrm{hg} / \mathrm{ml}$ ), compared with the control subjects with eosinophilic pulmonary infiltrate $(8 \mu \mathrm{g} / \mathrm{ml}$; range $5-10 \mathrm{hg} / \mathrm{ml})$ (table), and with the three normal subjects $(2 \cdot 7 \mu \mathrm{g} / \mathrm{ml}$; range $2-3 \mathrm{hg} / \mathrm{ml})$. 


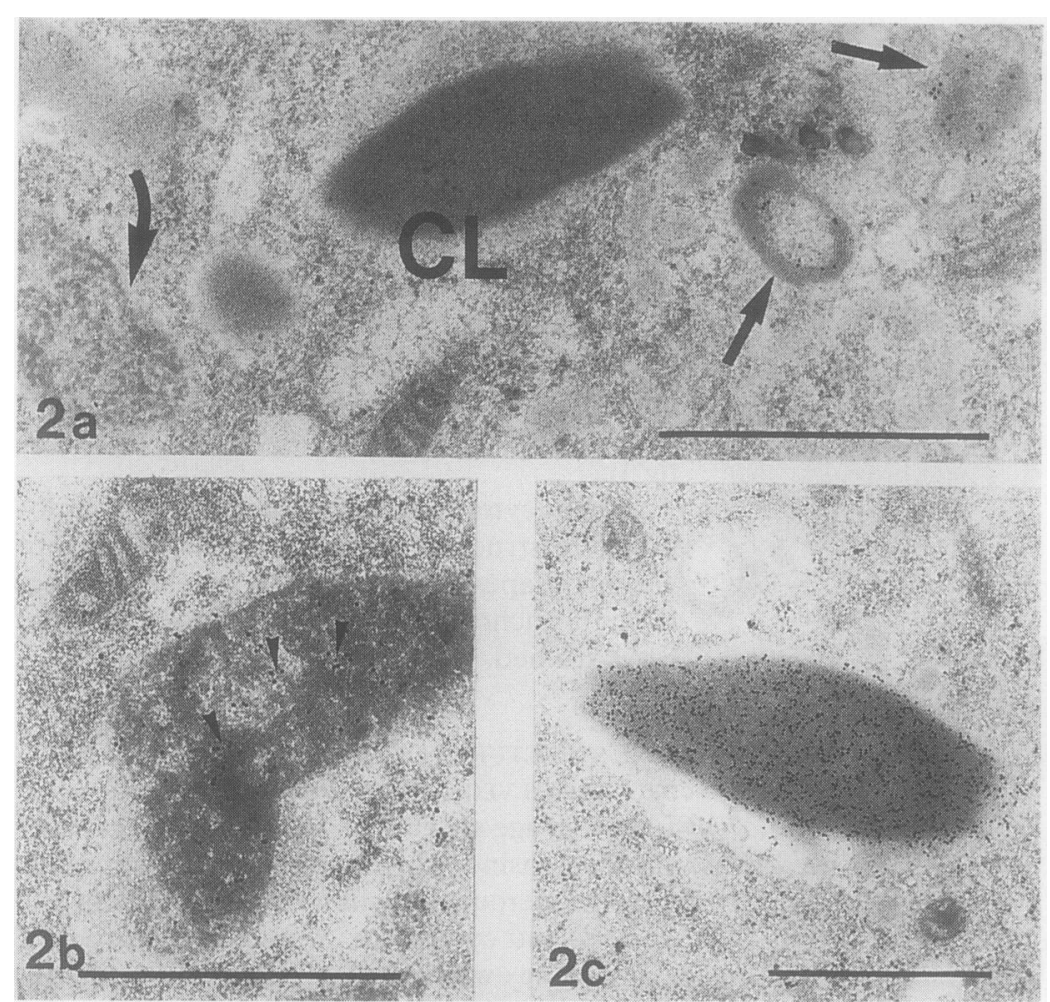

Figure 2 Selective redistribution of major basic protein $(M B P)$, eosinophil cationic protein (ECP), and Charcot-Leyden crystal (CLC) in macrophagic compartments. (a) Immunostaining with anti-MBP antibody: gold particles are detected on membranous structures (straight arrows), but not on Charcot-Leyden crystal (CL) or on granular round vacuoles (curved arrow), bar $=1 \mu \mathrm{m}$. (b) Immunostaining with anti-ECP antibody: gold particles (arrowheads) are localised on granular round vacuoles, bar $=1 \mu \mathrm{m}$. (c) Immunostaining with anti-CLC antibody: high concentration of gold particles on intraphagolysomal Charcot-Leyden crystal, bar $=1 \mu \mathrm{m}$.

\section{DISTRIBUTION OF MBP, ECP, AND CLC IN} MACROPHAGE CYTOPLASMIC COMPARTMENTS In the four cases of chronic eosinophilic pneumonia, immunostaining with the three different antibodies allowed the detection of gold particles within the cytoplasm of all macrophages in the bronchoalveolar lavage fluid (fig 2). Staining with anti-MBP antibodies

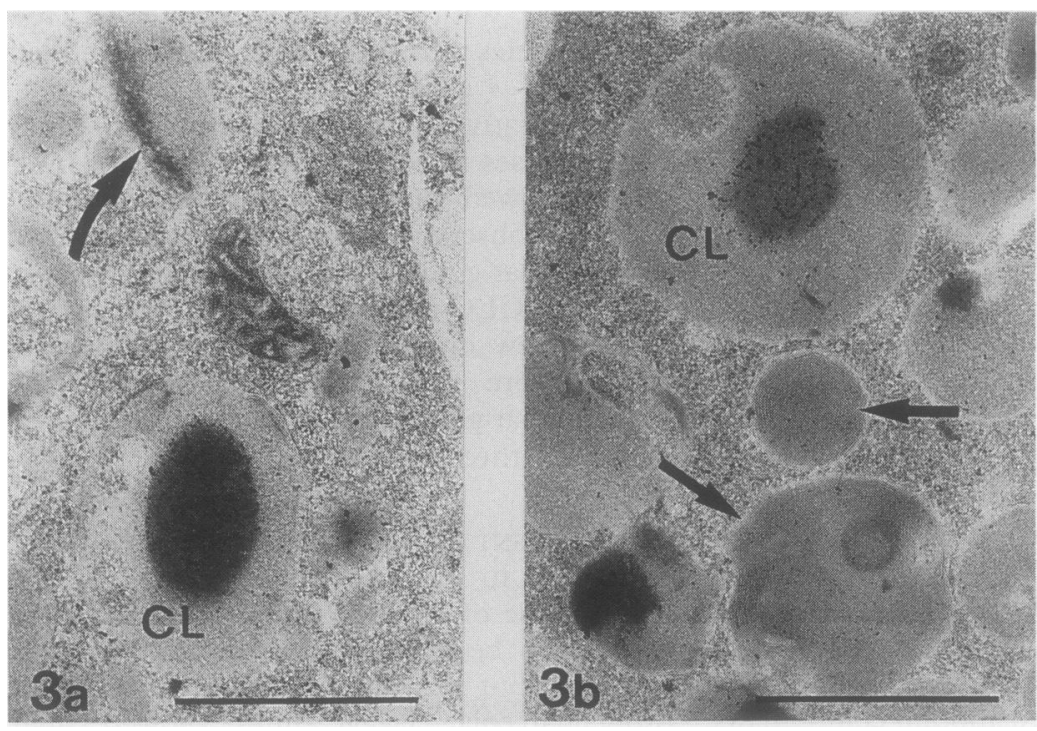

Figure 3 Selective distribution of Charcot-Leyden crystal (CLC) in macrophagic compartments. Even when the Charcot-Leyden crystal is not as well structured as in fig $2 c$, the CLC protein (CL) is immunodetected in specific lysosomal compartments. $(a)$ The macrophagic compartment containing CLC is different from the granular vacuoles (curved arrow) where eosinophil cationic protein (ECP) is detected as shown in fig $2 b$, bar $=1 \mu \mathrm{m}$. (b) The macrophagic compartment containing CLC is distinct from the pseudomyelinic structures (straight arrows), where major basic protein (MBP) was detected as shown in fig $2 a$. Bar $=1 \mu \mathrm{m}$. showed that this granular protein was distributed within the macrophage cytoplasm, but only on pseudomyelinic structures, and not on Charcot-Leyden crystals nor in vacuoles with a granular content (fig 2a).

Staining with anti-ECP antibodies showed that this component of the granule matrix was selectively distributed on the macrophage vacuoles with a coarse granular content (fig $2 b$ ) but neither on Charcot-Leyden crystals nor on pseudomyelinic structures. With anti-CLC antibodies, gold particles were concentrated on macrophage vacuoles with a well delineated crystal (fig 2c). They were also found on macrophage vacuoles with a dense, homogeneous content (figs 3a and b), but neither on granular vacuoles (fig 3a) nor on pseudomyelinic structures (fig 3b).

In the four control cases of eosinophilic pulmonaryinfiltrates, no gold particles could be detected in the macrophages in the bronchoalveolar lavage fluid after incubation with antiMBP, anti-ECP, or anti-CLC antibodies.

\section{Discussion}

This analysis of bronchoalveolar lavage fluid in four cases of chronic eosinophilic pneumonia studied eosinophils mixed with alveolar macrophages, as opposed to former studies on purified eosinophil populations. It showed important ultrastructural alterations of eosinophils, the release of three eosinophil proteins, and the distribution of these three proteins in different macrophage compartments. These features were not observed in the four control patients with eosinophil pulmonary infiltrate.

Cytoplasmic damage of eosinophils in chronic eosinophilic pneumonia has been previously reported histologically as part of "eosinophilic microabscess" in the lung, ${ }^{7}$ and ultrastructurally as numerous free eosinophil granules. $^{1213}$

In vitro, a predominant "hypodense" eosinophil population has been seen in bronchoalveolar lavage fluid of active cases, suggesting an activation process of eosinophils in this disease. ${ }^{1}$ In the four cases of chronic eosinophilic pneumonia in this study, eosinophil activation was further suggested by the presence of numerous free granules, release of three eosinophil proteins, and a significant increase in the concentration of ECP in bronchoalveolar lavage fluid compared with the control cases and the three normal controls.

Another type of eosinophil activation is the "piecemeal degranulation" observed in human cord blood eosinophils cultured with interleukin $5{ }^{21}$ This type of activation with intact cytoplasm containing electronlucent granules has also been found in eosinophilic gastritis, ${ }^{22}$ coeliac disease, ${ }^{23}$ and Crohn's disease. ${ }^{24} \mathrm{We}$ did not find any evidence of this type of eosinophil activation in our patients with chronic eosinophilic pneumonia. In this disease, the release of cationic proteins appears to result from the liberation of the whole granule following eosinophil lysis. Eosinophil degranulation associated with cell lysis, as seen in chronic eosinophilic pneumonia, may reflect a relatively higher 
degree of eosinophil activation than is seen in patients with eosinophilic pulmonary infiltrates.

Interactions between eosinophils and macrophages in chronic eosinophilic pneumonia have been reported previously. Ultrastructural studies have shown phagocytosed eosinophil granules and Charcot-Leyden crystals within lung macrophages. ${ }^{1013}$ In vitro studies have demonstrated that supernatants of alveolar macrophages obtained from active chronic eosinophilic pneumonia are able to stimulate eosinophil chemoluminescence. ${ }^{1}$ Indirect immunofluorescence on lung sections and the presence of $\mathrm{MBP}$ in pleural fluid ${ }^{25}$ have further confirmed eosinophil degranulation and activation in chronic eosinophilic pneumonia. In the present study, both MBP and ECP were released from free eosinophil granules in the extracellular space. These two cationic proteins were both phagocytosed; however, they were distributed in different macrophage compartments. MBP was selectively redistributed in pseudomyelinic structures, while ECP was concentrated in coarse granular inclusions, previously observed ultrastructurally in macrophages of patients with chronic eosinophilic pneumonia. ${ }^{11}$

Even though distributed in macrophage compartments, both MBP and ECP retained their antigenic structures, as they were still detected by their respective specific antibodies. These antigenically intact cationic proteins did not appear to exert their cytotoxic properties on the host macrophages. Recent studies have demonstrated that eosinophil MBP can activate neutrophils in a non-cytolytic fashion. ${ }^{26}$ Eosinophils in chronic eosinophilic pneumonia might activate pulmonary macrophages in a similar manner.

Eosinophil CLC protein showed a different type of interaction between eosinophils and lung macrophages in chronic eosinophilic pneumonia. This protein, biochemically different from $\mathrm{MBP},{ }^{27}$ is the constituent of Charcot-Leyden crystals, ${ }^{28}$ which are easy to detect microscopically. Since CLC is found in the whole cytoplasm of intact eosinophils and is not associated with a cytoplasmic structure, ${ }^{29}$ detection of CLC protein release is a good marker of eosinophil lysis. In the four cases of chronic eosinophilic pneumonia, the released CLC protein was phagocytosed and concentrated in macrophagic vacuoles. Similar results suggesting active sequestration of eosinophil CLC by macrophages has been shown in a model of human cord blood culture. ${ }^{21}$ Combined study of ECP, MBP, and CLC showed that, in the four cases of chronic eosinophilic pneumonia, CLC sequestration took place in macrophage vacuoles which did not contain MBP or ECP. This might imply a distinct role for CLC, MBP, and ECP in eosinophil-macrophage interactions.

These three proteins might be the effectors of a possible pathological role of eosinophil in chronic eosinophilic pneumonia. ${ }^{25}$ Although it has been proposed that eosinophils cause tissue damage in chronic eosinophilic pneumonia, ${ }^{12}$ it has not been demonstrated that the number or state of activation of eosinophils in bronchoalveolar lavage fluid are related to impaired lung function in this disease in the way they are in idiopathic pulmonary fibrosis. ${ }^{30} 31$ In chronic eosinophilic pneumonia, the uptake and selective distribution of the three eosinophil proteins in different macrophage compartments might protect the alveolar wall by preventing the high extracellular concentration of eosinophil proteases which is necessary for these proteins to exert their cytotoxic effects on lung parenchyma. ${ }^{32}$

Our results emphasise the high degree of activation of eosinophils in chronic eosinophilic pneumonia and their interaction with alveolar macrophages. Although many functions have been proposed, evidence now suggests that, as effector cells, eosinophils can have roles that are both beneficial and detrimental to the host. ${ }^{33}$ Eosinophils may have a collaborative role with macrophages involved in lung immune response in chronic eosinophilic pneumonia.

The authors thank D Pagniez and R Lafyatis for critica review of the manuscript, and A Plockin for the photographs.

1 Prin L, Capron M, Gosset P, Wallaert B, Kusnierz JP, Bletry $\mathrm{O}$, et al. Eosinophilic lung disease: immunological studies of blood and alveolar eosinophils. Clin Exp Immunol 1986;63:249-57.

2 Pexi A, Bertorelli G, Manganelli P, Mori PA, Strinati F, Marangio $\mathrm{E}$, et al. Bronchoalveolar lavage in chronic eosinophilic pneumonia. Analysis of 6 cases in comparison with other intestinal lung diseases. Respiration ison with othe
$1988 ; 54: 16-22$.

3 Liebow AA, Carrington CB. The eosinophilic pneumonia. Medicine (Baltimore) 1969;48:251-85.

4 Carrington CB, Addington WW, Goff AM, Madoff IM, Marks A, Swaber JR, et al. Chronic eosinophilic pneumonia. N Engl J Med 1969;280:788-98.

5 Rogars RM, Christiansen JR, Coalson JJ, Patterson CD. Eosinophilic pneumonia. Physiologic response to steroid therapy and observations on light and electron microscopic findings. Chest 1975;68:665-71.

6 Pearson DJ, Rosenow EC. Chronic eosinophilic pneumonia (Carrington's). A follow-up study. Mayo Clin Proc 1978; 53:73-8.

7 Jederlinic PJ, Sicilian L, Gaensler EA. Chronic eosinophilic pneumonia. A report of 19 cases and a review of the literature. Medicine 1988;67:154-62.

8 Gleich GJ, Adolphson CR. The eosinophil leucocyte structure and function. Adv Immunol 1986;39:177-253.

9 Prin L, Charon J, Capron M, Gosset P, Taelman H, Tonnel $\mathrm{AB}$, et al. Heterogeneity of human eosinophils. II Variability of respiratory burst activity related to cell density. Clin Exp Immunol 1984;57:147-55.

10 Kanner RE, Hammar SP. Chronic eosinophilic pneumonia. Ultrastructural evidence of marked immunoglobulin production plus macrophagic ingestion of eosinophils and eosinophilic lysosomes leading to intracytoplasmic Charcot-Leyden crystals. Chest 1977;71:95-8.

11 Quinonez GE, Sinion GT, Kay JM. Electron microscopy of chronic eosinophilic pneumonia. Clin Invest Med 1986; 9:238-43.

12 Fox B, Seed WA. Chronic eosinophilic pneumonia. Thorax 1980;35:570-80.

13 Gonzalez EB, Swedo JL, Rajaraman S, Daniels JC, Grant JA. Ultrastructural and immunohistochemical evidence for release of eosinophilic granules in vivo: cytotoxic potential in chronic eosinophilic pneumonia. J Allergy Clin Immunol 1986;79:755-62.

14 Spry CJ. Eosinophils. A comprehensive review and guide to the scientific and medical literature. Oxford: Oxford the scientific and medical liter

15 Capron M, Grangette C, Torpier G, Capron A. The second receptor for IgE in eosinophil effector function. Chem Immunol 1989;47:128-78.

16 Gleich GJ, Frigas E, Loegering DA, Wassom DL, Steinmuller D. Cytotoxic properties of the eosinophil major basic protein. $J$ Immunol 1979;123:2925-31.

17 Motojima S, Frigas E, Loegering DA, Gleich GJ. Toxicity of eosinophil cationic proteins for guinea pig tracheal epithelium in vitro. Am Rev Respir Dis 1989;139:801-5.

18 Khalife J, Capron M, Cesbron JY, Tai PC, Taelman H, Prin $\mathrm{L}$, et al. Role of specific IgE antibodies in peroxidase 
(EPO) release from human eosinophils. $J$ Immunol 1986; 137:1659-67.

19 Tomassini M, Tsicopoulos A, Po Chun Tai, Gruart V, Tonnel AB, Prin L, et al. Release of granule proteins by eosinophils from allergic and non allergic patients with eosinophilia upon immunoglobulin dependent activation. J Allergy Clin Immunol 1991;88:365-375.

20 Dvorak AM, Furitsu T, Letournesu L, Ishisaka T, Ackerman SJ. Mature eosinophils stimulated to develop in human cord blood mononuclear cell cultures supplemented with recombinant human interleukin 5. Part 1. Piecemeal degranulation of specific granules and distribution of Charcot-Leyden crystal protein. Am J Pathol 1991;138:69-82.

21 Dissous C, Torpier G, Duvaux-Miret O, Capron A. Structural homology of tropomyosins from the human trematode Schistosoma mansoni and its intermediate host Biomphalaria glabrata. Mol Biochem Parasitol 1990; 43:245-56.

22 Torpier G, Colombel JF, Mathieu-Chandelier C, Capron M, Dessaint JP, Cortot A, et al. Eosinophilic gastroenteritis: ultrastructural evidence for a selective release of eosinophilic major basic protein. Clin Exp Immuno 1988;74:404-8

23 Colombel JF, Janin A, Torpier G. Activated eosinophils in coeliac disease. Gut 1990;31:583-4.

24 Dvorak AM. Ultrastructural evidence for release of major basic protein-containing crystalline cores of eosinophil granules in vivo: cytotoxic potential in Crohn's disease. J Immunol 1980;125:460-2.

25 Grantham JG, Meadows JA, Gleich GJ. Chronic eosino- philic pneumonia. Evidence for degranulation and release of major basic protein. Am J Med 1986;80:89-94.

26 Moy JN, Gleich JG, Larry LT. Noncytotoxic activation of neutrophils by eosinophil granule major basic protein Effect on superoxide anion generation and lysosomal enzyme release. $J$ Immunol 1990;145:2626-32.

27 Ackerman SJ, Loegering DA, Gleich GJ. The human eosinophil Charcot-Leyden crystal protein: biochemical characteristics and measurement by radioimmunoassay. J Immunol 1980;125:2118-26.

28 Weller PF, Goetzl EJ, Austen KF. Identification of human eosinophil lysophospholipase as the constituent of Charcot-Leyden crystals. Proc Natl Acad Sci USA 1980; 77:7440-3.

29 Weller PF, Bach D, Austem KF. Expression of lysophospholipase activity by intact human eosinophils and their Charcot-Leyden crystals. Trans Assoc Am Phys 1981; 94:165-71.

30 Peterson MW, Marty M, Hunninghake GW. Prognostic role of eosinophils in pulmonary fibrosis. Chest 1987;92:51-6.

31 Hallgren $R$, Bjermer $L$, Lundgren $R$, Venge $P$. The eosinophil component of the alveolitis in idiopathic pulmonary fibrosis. Signs of eosinophil activation in the lung are related to impaired lung function. Am Rev Respir Dis 1989;139:373-8.

32 Ayars GH, Altman LC, Gleich GJ, Loegering DA, Bake CB. Eosinophil- and eosinophil granule-mediated pneumocyte injury. J Allergy Clin Immunol 1985;76: pneumocy

33 Weller PF. The immunobiology of eosinophils. N Eng J Med 1991;324:1110-18. 